\title{
GESTÃO COLETIVA NA OI KABUM! BH - A CONSTRUÇÃO DE SABER PELO FAZER COMPARTILHADO
}

Débora Bráulio Santos ${ }^{\mathrm{i}}$

\section{Introdução}

O envolvimento dos sujeitos que compõem a comunidade escolar em discussões e tomadas de decisão coletivas são crescentemente percebidos como cruciais para o bom funcionamento das instituições de ensino e para a plena efetividade dos processos educativos. A Oi Kabum! - Escola de Arte e Tecnologia de Belo Horizonte traz em seu projeto pedagógico uma proposta de Gestão Coletiva cujo objetivo é envolver, além da coordenação, alunos, educadores, funcionários, familiares e a comunidade em geral nos processos de gestão da escola, favorecendo seu envolvimento nas questões de interesse comum e contribuindo para que se sintam agentes ativos na constituição daquele espaço que constroem conjuntamente. A experiência de participação parece se mostrar condição fundamental para o exercício pleno da cidadania no âmbito de outras relações que extrapolam o ambiente escolar.

Mas essa proposta desafia valores e comportamentos tradicionais fortemente incorporados pelos sujeitos e estabelecidos não apenas na área de educação, mas na sociedade como um todo, pautados por hierarquias rigidamente estabelecidas e incontestadas, méritos e responsabilidades individualizados, competitividade e desmotivação para a participação. $\mathrm{O}$ encontro com essa outra lógica de organização sociopolítica faz emergirem dificuldades e desafios, ao mesmo tempo em que possibilita novos olhares sobre a educação. Discutiremos aqui os principais fatores em jogo em uma proposta de Gestão Coletiva, demonstrando a importância da experiência de participação na formação dos jovens, mas também os desafios envolvidos na efetivação da proposta.

\section{A Oi Kabum!, o Oi Futuro e a Associação Imagem Comunitária}

A Oi Kabum! é uma escola de arte e tecnologia criada em 2001 pelo Instituto Oi Futuro $^{i i}$, como um programa educativo em arte que visa promover o desenvolvimento integral das potencialidades de jovens por meio da expressão criativa. A escola busca instigá-los a se apropriarem com fluência das tecnologias da comunicação e da informação em processos de criação artística. 
A escola trabalha com alunos e egressos do Ensino Médio em escolas públicas. Os jovens especializam-se em uma de cinco linguagens - Design Gráfico, Webdesign, Computação Gráfica, Vídeo e Fotografia - e participam das atividades em quatro núcleos transversais: História da Arte e Tecnologia, Ser e Conviver, Oficina da Palavra e Design Sonoro. Os jovens integram ainda os Grupos de Gestão, formados por educadores e educandos, que têm por objetivo gerir as diversas áreas de funcionamento da escola. Tais atividades são distribuídas em uma carga-horária semanal de 20 horas. A base do processo formativo tem duração de 18 meses, sendo que, transcorrido esse período inicial, cada jovem tem a opção de integrar um Núcleo de Produção pelo período de mais 18 meses, vivenciando experiências profissionais ligadas às linguagens artísticas da escola.

O programa de formação foi idealizado e estruturado pelo Instituto Oi Futuro, responsável pelo acompanhamento, avaliação e pelos custos de manutenção. Existem quatro escolas no Brasil: em Belo Horizonte, Rio de Janeiro, Salvador e Recife. A tarefa de implementar o programa em contextos específicos cabe a ONGs parceiras, que se valem de seu know how metodológico para cumprir os objetivos estabelecidos. Na capital mineira, a $\mathrm{Oi}$ Kabum! é fruto da parceria do Oi Futuro com a Associação Imagem Comunitária (AIC) ${ }^{\mathrm{iii}} \mathrm{e}$ com o PLUG MINAS ${ }^{\text {iv }}$. A Associação Imagem Comunitária - Grupo de Pesquisa e Experimentação em Mídias de Acesso Público é uma ONG que atua desde 1993 na luta para promover o acesso público à comunicação baseado na produção coletiva, bem como na criação de experimentações estético-expressivas em diferentes mídias.

A AIC sempre procurou aliar as intervenções sociais presentes em seus projetos à produção de conhecimento a partir dos mesmos. No olhar da AIC, a Oi Kabum! BH se mostra como uma experiência educativa privilegiada para a realização desta pesquisa e os saberes gerados nesse ambiente têm muitas contribuições a dar para a educação brasileira. Por isso, foi idealizado um projeto de pesquisa para a escola, que possui três eixos - Gestão Coletiva; Juventude e Trabalho e Métodos de Ensino de Arte e Tecnologia. Este artigo é o produto final da pesquisa realizada dentro do tema Gestão Coletiva.

\section{Métodos da Pesquisa}

Para desenvolver esta pesquisa, escolhemos o método de abordagem qualitativa, por privilegiar o aprofundamento das análises, o contato direto e prolongado com o campo e com os sujeitos. Em tal abordagem, a "ênfase recai sobre a compreensão das intenções e do significado dos atos humanos", cujo sentido não se dá a conhecer de modo imediato (AlvesMazzotti, 1999, p. 131). Foram utilizados procedimentos como descrições detalhadas de 
situações, eventos, atitudes, interações e citações diretas de relatos dos sujeitos. As etapas seguidas na pesquisa foram as seguintes:

observação inicial - com duração de um mês e em caráter de busca, consistiu no acompanhamento das práticas pedagógicas diárias da escola, sem roteiro definido e registrando tudo o que se mostrava relevante. Este momento contribuiu na fase de planejamento das ações seguintes pela identificação de espaços formativos e processos a serem acompanhados com mais profundidade.

observação participante - acompanhamento de atividades pedagógicas e processos formativos (definidos a partir da observação inicial) de modo mais direcionado, focando em momentos que melhor poderiam subsidiar as análises. A pesquisadora colocava questões e interagia com os sujeitos, identificando indivíduos e/ou grupos cujos comportamentos interessavam às análises. A partir dela, foram identificados temas e questões a serem abordadas e assim construídos os roteiros para as entrevistas e grupos focais;

entrevistas semi-estruturadas - conversas orientadas por um pré-roteiro de questões (anexo 1), mas abrindo-se para desvios de rota de acordo com a dinâmica da conversa; grupos focais $^{v}$ - debates entre a pesquisadora e um grupo de indivíduos (escolhidos de modo dirigido ou aleatório) com questões lançadas aos participantes (anexo 2) de modo a favorecer a troca livre de argumentos. Os grupos focais foram gravados em áudio e mediados pela própria pesquisadora, que também fez a sistematização e análise do material;

consulta de documentos - realizada ao longo de todas as etapas, consistiu no acesso a documentos que contribuem para a compreensão dos princípios que guiam o funcionamento geral da Oi Kabum! BH, como o Projeto Pedagógico, relatórios produzidos pela equipe sobre os processos formativos, atas de assembleias e reuniões, entre outros.

\section{A Gestão Coletiva na Oi Kabum! BH}

A proposta de Gestão Coletiva na Oi Kabum! BH se baseia na organização da comunidade escolar em Grupos de Gestão, que fazem parte da grade curricular da escola. Trata-se de uma carga horária dedicada diretamente à gestão, bem como à reflexão sobre suas dinâmicas de funcionamento, o que inclui: a infra-estrutura e a organização da escola, políticas de uso e compartilhamento de espaços e equipamentos, sistemas de circulação de informações e tomadas de decisão sobre temas de interesse coletivo.

Os grupos contam com a presença de oito a doze jovens e um ou dois educadores, coordenadores ou membros da equipe técnica, que exercem ali a função de orientadores, isto é, não centralizam funções nem responsabilizem-se individualmente pelas tarefas do grupo, 
visto que o objetivo é promover o desenvolvimento, pelos jovens, da autonomia e capacidade de auto-gestão por meio da divisão de responsabilidades. A participação se dá prioritariamente a partir da escolha dos próprios jovens. Os Grupos de Gestão não possuem eixos temáticos fixos (com exceção do Conselho Gestor, explicado adiante), podendo ser reconfigurados de tempos em tempos. Boa parte dos grupos, porém, foi criada no início da escola e se mantém até hoje. Os grupos em atividade atualmente são: Conselho Gestor, Comunicação, Biblioteca, Equipamentos, Práticas Sustentáveis, Escambo de Saberes, Em Diálogo, Montagem de Exposições, Pesquisa e Cineclube. Os encontros são semanais, com uma carga horária de $1 \mathrm{~h} 50$, no total de $112 \mathrm{~h}$ ao longo de toda a formação.

Perpassando as ações de todos esses grupos, e com um papel central na proposta de Gestão Coletiva, está o Conselho Gestor, uma instância de representatividade dos jovens em diálogo com a coordenação. Diferente dos demais grupos, o mecanismo para a participação é eleitoral. Os interessados se candidatam e os jovens votam nos colegas que irão representá-los nessa instância. São eleitos dois representantes de cada turma, em um total de 10 a 12 jovens, cuja função é levar demandas, problemas, temáticas e sugestões para a pauta de discussão do Conselho. Eles têm também a função de informar e dialogar sobre as discussões realizadas, dando retorno aos colegas sobre o que foi deliberado.

Segundo o projeto pedagógico, os principais objetivos do Conselho Gestor são "promover a tomada de decisões compartilhadas sobre questões que dizem respeito ao funcionamento da escola", "possibilitar o planejamento conjunto de ações e estratégias para o uso dos recursos disponíveis" e "acompanhar as atividades dos outros grupos, núcleos e espaços da escola".

\section{A construção da autonomia e da atuação coletiva}

Como evidencia o Projeto Pedagógico, a aposta na importância dos Grupos de Gestão para a formação dos jovens busca desenvolver, de modo mais profundo, a autonomia, a capacidade de argumentação e o envolvimento com o coletivo, extrapolando a formação em arte para desenvolver aprendizados sociopolíticos e de relacionamento interpessoal.

O conceito de autonomia aqui utilizado se baseia no pensamento de Paulo Freire e se refere a um processo de construção da liberdade (em relação às determinações e condições objetivas do mundo) que se dá pela experiência da tomada de decisão e da reflexão crítica aliada à prática (o que define o conceito de práxis). Na visão de Freire, a autonomia vai sendo gradualmente construída pelos sujeitos em formação na medida em que estes encontram possibilidades de escolha, ou seja, na medida em que não são privados do direito à liberdade 
de tomar decisões. "Ninguém é autônomo primeiro para depois decidir. A autonomia vai se construindo na experiência de várias, inúmeras decisões que vão sendo tomadas (FREIRE, 1996, pg. 66, 67)".

Mas o conceito de autonomia, em Freire, não possui uma dimensão unicamente individual, mas também uma dimensão coletiva, social e política, que reside em sua ligação com a ética. Isso se deve à consciência do que o autor chama de "inacabamento" do homem enquanto ser cultural e histórico: "o inacabamento de que nos tornamos conscientes nos fez seres éticos" (FREIRE, 1996, pg. 35). A autonomia não é sinônimo de independência, na medida em que somos seres dependentes dos outros com quem nos relacionamos e fortememente influenciados pelas condições objetivas do mundo (econômicas, sociais, políticas, históricas etc). Porém não somos determinados, pois somos "capazes de intervir no mundo, de comparar, de ajuizar, de decidir, de romper, de escolher" (FREIRE, 1996, pg. 30). A possibilidade de escolher, de decidir (ou seja, a própria autonomia) é portanto a possibilidade de agir no mundo. A autonomia está assim diretamente ligada à ética e ao mundo compartilhado dos homens.

Nesta pesquisa, começamos por buscar respostas possíveis para a seguinte questão: o que vem a ser, exatamente, o que a Oi Kabum! BH chama de Gestão Coletiva? Partimos em busca do olhar dos jovens sobre ela - sua proposta, seus objetivos, limites e possibilidades. Percebemos que a noção de Gestão Coletiva era justamente associada a dois conceitos principais: tomada de decisão e ações coletivas. Era bastante compartilhada entre os jovens a ideia de que a Gestão Coletiva implica que, no processo decisório, a opinião de todas as pessoas concernidas no assunto em questão deve ser ouvida. Também era comum a compreensão de que ela implica que as decisões sejam tomadas sempre tendo em vista o bem coletivo. O fim último de toda decisão é "o que é melhor para toda a escola", e todos devem sempre "pensar no bem da maioria". Perguntados sobre o que seria a Gestão Coletiva na Oi Kabum! BH, alguns jovens responderam:

Jovem 1: "É quando é a opinião de todo mundo, a gente vai conversar com todo mundo pra ver o que vai fazer... É quando todo mundo pensa no bem da maioria".

Jovem 2: "Acho que está dentro disso mesmo, da gente conversar com todo mundo para ver o que vai fazer, já que não é só para o nosso grupo, é uma coisa que vai ser para a escola toda. Então a gente tenta, pegando esse pouquinho de gente que é do grupo, ter uma visão que seria melhor para a escola toda". (Grupo Focal sobre Gestão Coletiva, $2^{\circ}$ semestre/ 2011)

Notamos que, em um período relativamente curto de permanência na escola, os jovens se apropriam de certos preceitos básicos da proposta, que passam a ser compartilhados e utilizados para nortear suas ações. Eles demonstram compreender a importância de um sistema de organização coletiva que dê voz a todos, que favoreça a troca de argumentos, que 
tenha razões claras, decisões justificadas, abertura para a diversidade de pontos de vista e no qual o fim último seja o bem coletivo.

Os jovens também demonstram a compreensão de que, mesmo garantindo que o processo deliberativo tenha tais características, é impossível (e mesmo indesejável) que se alcance o consenso. Sempre haverá pessoas insatisfeitas com as decisões e é preciso reconhecer a importância da discordância para o aprendizado coletivo, já que ela pressupõe um esforço de diálogo que gera deslocamentos e demanda abertura e flexibilidade. Além disso, mesmo insatisfeitas, as pessoas tendem a aceitar as decisões, na medida em que o processo tiver ocorrido segundo os preceitos acima identificados, pois eles garantem legitimidade às decisões. Nesse sentido, a fala de uma jovem entrevistada é exemplar:

\footnotetext{
"Eu acho que é quando há uma conversa, um diálogo sobre determinado assunto, e a decisão é tomada de acordo com isso... Não é que todos vão estar de acordo, que vai ser com o consenso de todo mundo, mas quando aquilo é feito de uma forma que todos estão cientes do que vai acontecer, como vai acontecer, e porque vai acontecer" (Entrevista individual com jovem).
}

Outro aspecto relevante para o processo deliberativo, do qual os jovens demonstram ter consciência, é de que algumas questões, por seu nível de complexidade, demandam um tempo mais estendido para o debate. Há certos assuntos sobre os quais é preciso se debruçar com cuidado, considerá-lo sob diversas facetas, rever opiniões, sendo que uma decisão precipitada pode gerar complicações futuras. A fala de uma jovem explicita esse ponto:

"Eu acho que alguns assuntos a gente deve ter a conversa até cansar, até chegar ao final. Nunca vai ter todo mundo concordando, pois é democracia. Mas acho que, quando é compartilhado, as opiniões devem ser expostas e argumentadas até o fim, até a pessoa comprar a opinião do outro. Da mesma forma que a gente passou o semestre inteiro discutindo sobre a questão do corte da bolsa". (Entrevista individual com jovem)

A tomada de decisão relativa ao desconto na bolsa devido a faltas e atrasos foi uma situação exemplar. Trata-se de um tema delicado, que gerou um longo debate envolvendo a maior parte dos jovens da escola, educadores e coordenação, via Conselho Gestor. A questão dizia respeito à criação de uma política pela qual o valor mensal recebido pelo jovem por sua bolsa de estudos na Oi Kabum! BH sofreria desconto de acordo com a quantidade de faltas e atrasos que ele apresentasse durante o mês. A questão envolvia variáveis importantes, como os motivos para as faltas e atrasos, a oferta de contrapartidas para compensar as ausências, o valor que deveria ser descontado e as consequências desse desconto para cada jovem. A discussão sobre o tema foi longa, o que permitiu que todos os envolvidos expressassem seus 
pontos de vista e compreendessem as razões oferecidas, e que, ao fim do processo, os jovens diretamente afetados legitimassem a política construída (mesmo aqueles que, a princípio, não concordavam com ela).

Foi interessante notar, por suas falas, que os jovens tinham clara consciência de que o resultado satisfatório da decisão se devia ao modo como ela foi tomada, isto é, atendendo aos preceitos fundamentais da deliberação democrática. Este é o comentário de um jovem sobre o caso:

A decisão sobre o desconto na bolsa era uma decisão delicada, mas como foi discutida, todo mundo entendeu e concordou. Ela foi melhorando com os debates, ninguém se sentiu injustiçado. (Grupo Focal sobre Gestão Coletiva, $1^{\mathrm{o}}$ semestre/ 2011)

O conceito de democracia que norteia esta pesquisa se baseia na teoria de Boaventura Souza Santos. Ao discutir a emancipação social, o autor propõe um conceito de democracia que está relacionado às noções de autonomia e diálogo, porque ligado à pluralidade de vozes e olhares e à possibilidade de ação e tranformação do mundo. Santos argumenta que a luta política pela reinvenção da emancipação social e do conceito de democracia possui fortemente uma dimensão epistemológica, ligada à produção e à legitimação do conhecimento. Segundo o autor, nossa forma de ver e interpretar o mundo no Ocidente se baseia numa racionalidade que exclui e deslegitima diversas outras formas de conhecimento e de saber (como os populares, indígenas, camponeses e urbanos, bem como as práticas sociais baseadas nestes saberes), tornando-os invisíveis, ausentes da realidade: "o que não existe é produzido ativamente como não existente, como uma alternativa não crível, como uma alternativa descartável, invisível à realidade hegemônica do mundo" (SANTOS, 2007, pg. 28). O conceito de democracia, para Boaventura, está portanto ligado à possibilidade de que estas experiências, saberes e diferenças deslegitimados e invizibilizados possam emergir na realidade social e entrar em diálogo, de um ponto de partida igualitário, ou seja, sem que uns sejam considerados a priori mais válidos que outros.

\footnotetext{
há nos oprimidos aspirações que não são proferíveis, porque foram consideradas improferíveis depois de séculos de opressão. O diálogo não é possível simplesmente porque as pessoas não sabem o que dizer: não porque não tenham o que dizer, mas porque suas aspirações são improferíveis. E o dilema é como fazer o silêncio falar por meio de linguagens, de racionalidades que não são as mesmas que produziram o silêncio no primeiro momento. Esse é um dos desafios mais fortes que temos: como fazer o silêncio falar de uma maneira que produza autonomia e não a reprodução do silenciamento (SANTOS, 2007, pg. 55).
} 
Santos explica que a idéia de democracia sempre esteve ligada à metáfora do contrato social, ou seja, um compartilhar de direitos iguais que garantiria inclusão na sociedade. Porém, esta igualdade política, não sendo acompanhada de igualdade econômica, social e inclusive epistemológica e cognitiva, fez com o que o contrato social fosse sempre seletivo, excluindo "muita gente e muitos temas". A tese central do autor é de que é preciso reinventar a demodiversidade ${ }^{v i}$, ou seja, reconstruir algumas formas de democracia, e a principal delas seria fortalecer a participação e criar um vínculo entre esta e a representação. "Então, minha definição de democracia é: substituir relações de poder por relações de autoridade compartilhada" (SANTOS, 2007, pg. 62). A importância da participação residiria portanto na possibilidade de que as vozes, experiências, saberes e práticas não hegemônicas pudessem participar igualmente da construção coletiva do mundo social, em relações de autoridade compartilhada. Ou seja, todos devem ter autonomia suficiente para intervir e transformar a realidade a partir de suas "epistemologias", por meio do diálogo.

Cremos que esse é o princípio fundamental da epistemologia que lhes proponho e (...) que se baseia nesta ideia central: não há justiça social global sem justiça cognitiva global, ou seja, sem justiça entre os conhecimentos (SANTOS, 2007, pg. $40)$.

As falas dos jovens da Oi Kabum! BH demonstram que eles associam o conceito de democracia à possibilidade de expressão de opiniões e interpretações diversas e divergentes. Notamos assim que este processo deliberativo democrático é de fato eficaz para a construção da justiça social e cognitiva da qual fala Boaventura Santos.

\section{O caráter prático da Gestão Coletiva e a noção de práxis}

No Projeto Pedagógico da Oi Kabum! BH e nos demais textos e documentos da escola, encontramos definições gerais dos mecanismos que guiam os procedimentos dos Grupos de Gestão, além de justificativas para a adoção da proposta, mas não existem regras claras de conduta, modelos ideais de ação ou detalhamentos de como o sistema deve funcionar. A determinação de modelos procedimentais pode levar à cristalização de modos de agir. "O fechamento para os erros, como forma de evitar novos problemas, enseja a repetição e a cristalização de formas, conteúdos e processos de produção, o que os condena à obsolescência em maior ou menor prazo" (Melo et all., 2006, pg. 54). A aposta de que o erro, o acaso, o risco e o conflito não devem ser eliminados, pois é a partir deles que o novo pode surgir, é parte importante da proposta.

Além disso, a necessidade de que as regras não sejam impostas, prescritas, e sim discutidas e construídas coletivamente parte da aposta de que é neste movimento da 
participação que se faz a construção, lenta e gradual, da autonomia por parte dos educandos. Para Freire, a prescrição é um dos principais elementos que contribuem para a manutenção da opressão. "Toda prescrição é a imposição da opção de uma consciência a outra. Daí, o sentido alienador das prescrições" (FREIRE, 1987, pg. 18).

Sendo assim, evidenciou-se que, embora não exista nenhum manual sobre a prática da Gestão Coletiva, rapidamente os educandos demonstraram se apropriar dos pressupostos básicos da proposta. Mas se não existe uma transmissão teórica desses conteúdos, como os jovens os assimilam em tão pouco tempo, sendo mesmo capazes de expressá-los discursivamente?

Acreditamos que isso ocorre justamente porque não se trata de um aprendizado teórico, mas de vivências experimentadas diretamente por eles ao desempenhar tarefas diárias. Os Grupos de Gestão têm uma natureza essencialmente prática e, ao invés de discorrer sobre como eles devem funcionar, os educadores fazem com que os jovens partam para a ação e, ao longo dela, provocam-nos para agir e refletir tomando estes princípios como base.

Para Paulo Freire, ação e reflexão são indissociáveis e constituem o conceito de práxis, que novamente reforça a relação entre os conceitos de autonomia e de diálogo. Ao analisar a palavra, elemento primário do diálogo, Freire afirma que a palavra verdadeira é aquela que tem poder de transformação sobre a realidade, pois, quando descolada de seu elemento de ação, tem também o seu outro elemento (a reflexão) esvaziado, tornando-se discurso vazio e alienador. Mas o elemento de reflexão não é menos importante, pois o fazer descolado do pensar torna-se automatismo igualmente incapaz de transformação efetiva:

esgotada a palavra de sua dimensão de ação, sacrificada, automaticamente, a reflexão também, se transforma em palavreria, verbalismo, blablablá. Por tudo isto, alienada e alienante. É uma palavra oca, da qual não se pode esperar a denúncia do mundo, pois que não há denúncia verdadeira sem compromisso de transformação, nem este sem ação. Se, pelo contrário, se enfatiza ou exclusiviza a ação, com o sacrifício da reflexão, a palavra se converte em ativismo. Este, que é ação pela ação, ao minimizar a reflexão, nega também a práxis verdadeira e impossibilita o diálogo. (FREIRE, 1987, pg. 44)

Ao discutir a participação, Bordenave também se refere ao conceito de práxis e defende que esta é, como os demais processos sócio-humanos, algo que pode ser aprendido e aperfeiçoado.

Essas coisas não se adquirem numa sala de aula, mas na chamada práxis, que é um processo que mistura a prática, a técnica, a invenção e a teoria (...) Evidentemente, o tipo de educação que pode fomentar esses tipos de aprendizagem não é a educação tradicional, quer consista na transmissão pura e simples de conteúdos, quer na moldagem do comportamento humano com objetivos preestabelecidos. A participação não é um conteúdo que se possa transmitir (...) também não é uma 
destreza que se possa adquirir pelo mero treinamento. A participação é uma vivência coletiva e não individual, de modo que somente se pode aprender na práxis grupal. Parece que só se aprende a participar, participando. (DIAZ BORDENAVE, 1994, pg. 73)

É justamente por se tratar de um aprendizado prático e coletivo, vivenciado e construído ao longo da ação aliada à reflexão (que se materializa no diálogo e na argumentação), que esse conjunto de preceitos básicos da Gestão Coletiva, bem como os aprendizados que dele derivam, parecem ser apreendidos e compartilhados pela comunidade escolar com notável rapidez e consistência.

\section{A consciência dos fluxos da gestão e o cuidado com o espaço}

Além de experienciarem o processo de tomada de decisão, os jovens também vivenciam a complexidade dos fluxos de uma instituição, aprendendo como a lida com qualquer demanda passa por burocracias, requer negociações e está sujeita a procedimentos nem sempre imediatos ou de fácil resolução.

Um exemplo disso ocorre quando um jovem do grupo da Biblioteca acompanha o processo de compra de um livro. Orientados pelo educador responsável, ele e seus colegas fazem pesquisas de livrarias, levantam orçamentos, avaliam as condições de cada oferta, acompanham o processo de encomenda, entrega e recebimento, catalogam o livro e colocamno no acervo. O jovem então se dá conta de que o livro não "sai da livraria e aparece na prateleira da escola". Há um exigente processo envolvido na compra que o faz tomar consciência de que a resolução de demandas não é algo simples, o que o retira de uma postura confortável de exigência sem ação.

\footnotetext{
"O grupo te faz experimentar os dois lados: de quem quer a coisa e de quem sabe o processo necessário para ela. Normalmente, você quer uma coisa, mas não tem ideia do que é preciso para que aquilo aconteça, entende?" (Grupo Focal sobre Gestão Coletiva, $2^{\circ}$ semestre/ 2011)
}

Ao mesmo tempo, essa consciência da complexidade dos fluxos logísticos de todo processo (seja ele criativo, produtivo, administrativo ou de qualquer outra natureza) propicia aos jovens o desenvolvimento de habilidades de organização pessoal. Eles aprendem a estabelecer metas, criar estratégias para concretizá-las, seguir prazos, entender e expressar com mais clareza o que visam realizar.

"Hoje eu me exponho melhor até pra lidar na aula, eu acho que mudei pra melhor, os projetos que eu faço... Eu consigo planejar, escrever, colocar tudo no papel... 
Antes ficava tudo na cabeça, e agora me ajudou a negociar as coisas. Acho que me ajudou muito profissionalmente". (Entrevista individual com jovem)

Esse tipo de aprendizado tem reflexos diretos no mundo do trabalho, na formação de profissionais mais autônomos e com habilidades que extrapolam a atuação em áreas específicas, evitando a superespecialização e a fragmentação dos campos do saber e do fazer.

Outro aprendizado crucial resultante da experiência de gerir coletivamente diz respeito à conscientização acerca da importância do cuidado com o espaço que se ocupa e com a infraestrutura que se utiliza. Na medida em que passam a se ocupar de tarefas ligadas à manutenção, organização e conservação de equipamentos e locais da escola, os jovens sensibilizam seu olhar e se tornam mais atentos no uso dos mesmos, revendo hábitos e comportamentos inadequados ou danosos aos bens coletivos.

\footnotetext{
"Acho que quando a gente se sente mais inserido, fazendo mais parte da escola, a gente tem outro olhar sobre a questão de cuidado, de preservar mais, de preocupar mais com a escola". (Grupo Focal sobre Gestão Coletiva, $2^{\circ}$ semestre/ 2011)
}

O grupo de gestão de equipamentos traz um bom exemplo. Seus participantes cuidam do almoxarifado da escola, onde são armazenadas câmeras, microfones, computadores e todo tipo de equipamento. O grupo realiza tarefas de organização (identificação dos materiais por etiquetas, distribuição em caixas etc.), catalogação (levantamento de todo o acervo para compor uma planilha, controlando a entrada de novos equipamentos e a saída daqueles em uso) e desenvolvimento da política de uso (para acordar coletivamente as possibilidades de utilização pelos jovens, educadores e comunidade da escola em geral). É interessante notar a consciência que os jovens desse grupo ganham da importância do uso adequado dos equipamentos, como afirma uma educadora:

"É impressionante como os meninos do [Grupo de] Equipamentos aprendem a ter cuidado! Eles ficam loucos quando veem uma câmera jogada em cima da mesa depois da aula. Eles chamam a atenção de educador!" (Educadora do Grupo de Equipamentos)

O fato de os jovens experimentarem semanalmente a gestão dos equipamentos provoca uma sensibilização do olhar e uma mudança de atitude, com vistas a evitar os danos que eles sabem serem difíceis de resolver.

\section{A construção do desejo - Os Grupos de Gestão como espaço de transformação de interesses}


Ao longo da pesquisa, buscamos compreender o que motivava ou desmotivava os jovens a participar de um determinado grupo, investigando quais seriam os "atrativos" ou estratégias para favorecer o envolvimento e a cooperação, e quais fatores levariam a uma possível desmotivação ou desinteresse pela participação. Em entrevistas e grupos focais, foram feitas perguntas como: "por que você escolheu este Grupo de Gestão?" e "como vocês avaliam a participação de vocês na Gestão Coletiva?’. Estas foram algumas respostas:

\begin{abstract}
"Escolhi o cineclube porque a gente vai discutir sobre os filmes e eu acho que isso vai aumentar o meu conhecimento, assim, falando de vídeo". (Entrevista individual com jovem)

"Eu escolhi o grupo da Biblioteca no primeiro semestre, porque gosto de ler, de mexer com livros. Gostei do grupo e continuei nele no semestre seguinte". (Grupo Focal sobre Gestão Coletiva, $2^{\circ}$ semestre/ 2011)

"Entrei pro grupo de equipamentos porque era um gosto particular meu,gostei bastante dessa parte de equipamentos". (Grupo Focal sobre Gestão Coletiva, ${ }^{\circ}$ semestre/ 2012)
\end{abstract}

Entre todos os entrevistados e participantes de grupos focais, nenhum afirmou ter escolhido o grupo pensando primeiramente em contribuir com a gestão da escola. $A$ motivação inicial para a participação parte do interesse pessoal pelas vivências e aprendizados que oferecem e pela busca de novas habilidades e conhecimentos, bem como pelo gosto pessoal em desenvolver atividades que o jovem considera prazerosas.

A Oi Kabum! BH não considera problemática a associação entre atividades de interesse coletivo e desejos pessoais. Pelo contrário, a escola reconhece a necessidade de que a participação parta de uma motivação do sujeito, e não de uma imposição da coordenação ou do currículo escolar, determinando a escolha individual dos jovens como o principal critério para a seleção dos participantes. Evidencia-se a crença de que tanto o aprendizado quanto a participação estão diretamente ligados ao desejo, entendido como motivação pessoal para o engajamento.

Esta pesquisa mostrou que esta é uma escolha acertada. O fato de os Grupos de Gestão estarem conectados a interesses pessoais parece fazer com que a participação neles tenha um sentido, o que estimula a dedicação. Não se trata apenas de desempenhar tarefas para o bem coletivo - o que pode soar como um discurso pouco atraente para os jovens no início do processo formativo. Trata-se de realizar atividades por meio das quais eles fazem o que gostam e aprendem coisas que os interessam.

"Entrei pro grupo de montagem e fiquei nele por dois semestres. Eu acho que participo muito nele, gosto muito de contribuir, porque passei a considerar o grupo mais ainda como se fosse uma coisa que acrescentasse na minha formação. Eu não 
vou só ajudar a cuidar do acervo da escola, eu estou me formando junto com esse processo inteiro! A gente consegue estudar no grupo, atender as demandas da escola, a gente conseguiu montar uma exposição! No final, percebi que tudo fazia parte do processo formativo". (Grupo Focal sobre Gestão Coletiva, $1^{\circ}$ semestre/ 2012)

A experiência de participação que parte do desejo favorece a associação de tarefas coletivas com o sentimento de prazer. É interessante notar como, aos poucos, os jovens ganham consciência dessa associação e se sentem confortáveis em explicitá-la, argumentando que isso não indica uma postura individualista, mas uma escolha pessoal que não deixa de estar associada a benefícios coletivos.

\footnotetext{
"Eu acho que me sinto ativo nas questões que eu quero defender, nas questões que eu estou envolvido. Isso não é tanto uma coisa individual, os lugares que interessam a mim interessam a outras pessoas também. Por exemplo, eu me interesso por biblioteca e fotografia. Eu vou atuar mais nessa parte, tentar essa gestão da biblioteca e da fotografia, o que não é tão individual porque tem outras pessoas usando a biblioteca e o laboratório de fotografia". (Grupo Focal sobre Gestão Coletiva, $2^{\circ}$ semestre/ 2011).
}

Bordenave analisa as forças atuantes na dinâmica participativa de grupos humanos e afirma que "os membros de grupo participam mais intensamente quando percebem que o objetivo da ação é relevante para seus próprios objetivos" (DÍAS BORDENAVE, 1994, pg. 50). É de suma importância, no entanto, explicitar o que percebemos nesta pesquisa em relação a este elemento a que chamamos desejo, motivação ou interesse pessoal: trata-se de sentimentos continuamente construídos e modificados pelas experiências vividas pelos sujeitos. Os interesses de um indivíduo não são sentimentos estanques, resultantes de uma identidade intrínseca e imutável, mas sim construídas a partir de um conjunto de influências de caráter social, cultural, político e interpessoal. As aspirações de um indivíduo podem se modificar ao longo do tempo, diante de novos aprendizados e vivências.

Juarez Dayrell defende que, "no trabalho com os jovens, a força propulsora tem de ser o desejo". Tal desejo, no entanto, se modifica e se recria continuamente, pois a juventude é o momento em que o jovem se coloca questões como "quem sou?" e "para onde vou?" "questões cruciais que remetem à identidade e ao projeto de vida, duas dimensões que aparecem interligadas e são decisivas no processo de amadurecimento". Da mesma forma que os jovens desenvolvem, com a atuação nos grupos, sensibilidade para a importância das atividades coletivas (o que é favorecido pela possibilidade de escolherem atividades pelas quais se interessam), eles também desenvolvem novos interesses e desejos ao tomar contato com experiências que, a princípio, tenderiam a rejeitar. 


\section{A Gestão Coletiva rompe os muros da escola}

Outro foco desta pesquisa era investigar se os jovens se apropriavam dos aprendizados oriundos da Gestão Coletiva em outras dimensões de suas vidas e, sendo este o caso, como ocorreria tal apropriação. Percebemos que suas relações sociais e o modo como lidam com a vida em coletividade são influenciados pelas experiências vividas na Oi Kabum! BH de diversas formas.

De um lado, os jovens passam a identificar contextos, externos à Oi Kabum!, em que são levados em conta princípios semelhantes aos da proposta de Gestão Coletiva, que considera critérios como a participação dos envolvidos nas tomadas de decisão, a flexibilização das hierarquias, o respeito à diversidade e a capacidade de trabalhar em grupo. É o caso de uma jovem que, indagada sobre seu primeiro contato com a proposta de Gestão Coletiva, afirmou já ter vivido experiências semelhantes, porém sem esse nome.

\footnotetext{
"Eu já trabalhei numa escolinha e alguns assuntos a gente tratava assim, sentava e discutia todo mundo de igual pra igual. Vou dar outro exemplo da minha casa: a gente vive dessa forma, não há aquela hierarquia, pai, mãe pra tomar as decisões. Também na ONG onde eu faço parte a gente vai decidir os artistas que vão apresentar no dia da intervenção, o lugar, como vai ser o horário de cada um, o que vai acontecer, o tanto de verba que vai ser destinada para cada intervenção - tudo é discutido entre todos". (Entrevista individual com jovem)"
}

Por outro lado, percebemos também que os aprendizados relativos à Gestão Coletiva promovem mudanças nos comportamentos sociais dos jovens, modificando antigas formas de ver o mundo e de se relacionar. Eles passam a exigir em outras esferas de sociabilidade que as relações sejam pautadas por critérios democráticos, eles mesmos demonstrando o esforço para orientar suas ações nesse sentido. Uma jovem dá um exemplo desta aplicação no mundo profissional.

\footnotetext{
“O meu horário é $6 \mathrm{~h}$ da manha e já é pesado, tem de levantar às 4 h e ficar até $12 \mathrm{~h} 20$, o tempo todo olhando para uma tela de computador e com 40 minutos para você sair, tomar café e voltar. A gente tem que pensar em como alternar nossos horários para não atrapalhar o coleguinha. Pensar em como lanchar, como tirar as coisas de um sistema e transferir para o outro, como fazer o amigo oculto... E a minha equipe - que a gente considera que é uma das mais unidas na turma da manhã - consegue fazer tudo junto. A gente senta e conversa: 'vamos tentar fazer desse jeito. Se não der certo, a gente tenta de novo' e é a opinião de todo mundo. Eu aprendi isso: eu não quero esse jeito porque vou pensar no jeito que dê para todo mundo". (Entrevista individual com jovem)
}

Outra jovem falou da aplicação de conhecimentos ligados à Gestão Coletiva em sua escola regular: 
"Onde eu estudo tem uma turma querendo melhorar a escola, fazendo projetos pra ela recuperar o nome que ela tinha no passado. Eu levo muita coisa daqui pra lá, a coisa da gente levantar uma pauta e todo mundo falar, e depois levar pra coordenação pra chegar numa decisão pelo bem comum. (Entrevista individual com jovem)"

Notamos, assim, que em um período relativamente curto de experiência com a Gestão Coletiva, os jovens passam a identificar a importância e amplitude do aprendizado que ela traz - relativo às relações humanas, ao falar e ouvir, argumentar, pensar coletivamente. Tais aprendizados são rapidamente colocados em prática em suas vidas, em âmbitos de interação como família, trabalho, escola e relações interpessoais.

\section{Os desafios da Gestão Coletiva}

Certamente, são muitos os desafios que se colocam quando se opta por uma proposta pedagógica que cria espaços para que a divergência e o conflito emerjam e se tornem visíveis. Ao mesmo tempo em que constitui a essência da proposta, o conflito representa também um de seus principais desafios. Por um lado, ele se mostra necessário: é preciso que haja discordância para que haja negociação. Mas se não há regras pré-definidas, a todo tempo surgem dificuldades. Uma questão delicada, por exemplo, diz respeito à efetividade do poder de decisão dos jovens. Até que ponto a tomada de decisão está nas mãos deles? Em que áreas eles estão aptos a tomar decisões?

Devido a uma aposta na importância da participação dos jovens, não existem regras claras que definem o escopo desta. Tal aposta se deve à crença de que a melhor forma de se decidir sobre as prioridades de um determinado grupo é deixar que os próprios sujeitos se pronunciem sobre elas. Paulo Freire nos lembra que muitos planos políticos e docentes falharam porque seus realizadores partiram apenas de suas visões de mundo e "não levaram em conta, num mínimo instante, os homens em situação a quem se dirigia seu programa, a não ser como puras incidências de sua ação" (FREIRE, 1987, pg. 48). Ao falar da pedagogia crítica, libertadora, o autor ressalta que ela só pode ser pensada e construída pelos próprios oprimidos, por meio da prática da participação. Ela não pode ser elaborada pelos opressores, pois é precisamente "aquela que tem de ser forjada com ele e não para ele" (FREIRE, 1987, pg. 17).

Estando, porém, a princípio, aptos a participar de qualquer decisão, muitas vezes os jovens se mostram insatisfeitos com o tratamento dado a certas questões e julgam que sua participação foi limitada. Alguns educandos passam a questionar toda forma de autoridade e a demonstrar insatisfação com situações em que uma posição hierárquica pareça ter contribuído para o resultado de uma decisão. Por isso, é essencial aos educadores a consciência de que os educandos desenvolvem gradualmente a responsabilidade necessária para protagonizar deliberações de modo inteiramente autônomo, bem como a maturidade que lhes permite arcar com suas consequências. É preciso mediar as discussões e saber intervir quando necessário, assumindo sua responsabilidade como educador. 
O educando que exercita sua liberdade ficará tão mais livre quanto mais eticamente vá assumindo a responsabilidade de suas ações. (...) a autoridade coerentemente democrática jamais se omite. Se recusa, de um lado, a silenciar a liberdade dos educandos, rejeita, de outro, a sua supressão do processo de construção de boa disciplina. Um esforço sempre presente à prática da autoridade coerentemente democrática é o que a torna quase escrava de um sonho fundamental: o de persuadir ou convencer a liberdade de que vá construindo consigo mesma (...) a sua autonomia. (FREIRE, 1996, pg. 57)

Sendo assim, notamos que, no caso da Oi Kabum! BH, o objetivo central da Gestão Coletiva é mais pedagógico que institucional, ou seja, seu foco principal não é que todas as deliberações sejam inteiramente conduzidas pelos jovens, mas que eles aprendam sobre o processo de gestão e negociação de conflitos. O foco principal da Gestão Coletiva é o aprendizado, inclusive o de descobrir que é preciso respeitar fluxos decisórios, lidar com a frustração e desconstruir o imaginário de que participar de uma proposta de gestão coletiva significa decidir tudo coletivamente - ou a despeito de qualquer relação hierárquica. Os jovens devem construir, juntamente com sua liberdade, a maturidade e a responsabilidade necessárias para usufruir dela, bem como o respeito à hierarquia e à autoridade legítimas. Para o educador, a princípio aquele que detêm o saber e o poder de decidir, trata-se de reconhecer a autonomia daquele que ele tende a subjugar e abandonar lugares de poder e práticas educativas cristalizadas, utilizando sua autoridade de forma legítima.

Outra dificuldade se refere ao desequilibrio na capacidade de persuasão entre os participantes do debate - fator altamente influente no processo de tomada de decisão. Aqui é importante considerar um aspecto sociocultural que diz respeito à predominância, nas instituições em geral, de modelos de gestão com hierarquias rígidas, marcados pela meritocracia, o individualismo e a competitividade. $\mathrm{O}$ sistema educacional formal adota mecanismos que cerceiam o lugar de fala do jovem, dificultando a expressão de seu ponto de vista e sua atuação como sujeito autônomo.

Mas não podemos considerar os jovens a priori, por sua idade, sua origem social ou por sua inserção em uma sociedade em que dominam sistemas autoritários, como sujeitos incapazes de se pronunciar a respeito de seus próprios interesses. Jacques Rancière em $O$ Mestre Ignorante critica o modelo educacional que toma a desigualdade como princípio e aposta no processo formativo como meio de corrigi-la, pois, desta forma, tal modelo mina a igualdade em suas raízes, pretendendo reduzir algo que não cessa de reproduzir.

Quem estabelece a igualdade como objetivo a ser atingido, a partir da situação de desigualdade, de fato a posterga até o infinito. A igualdade jamais vem após, como resultado a ser atingido. Ela deve sempre ser colocada antes. (...) Não há ignorante que não saiba uma infinidade de coisas, e é sobre este saber, sobre esta capacidade em ato que todo ensino deve se fundar. Instruir pode, portanto, significar duas coisas absolutamente opostas: confirmar uma incapacidade pelo próprio ato que pretende reduzi-la ou, inversamente, forçar uma capacidade que se ignora ou se denega a se reconhecer e a desenvolver todas as consequências desse 
reconhecimento. O primeiro ato chama-se embrutecimento e o segundo, emancipação. (RANCIÈRE, 2010, pg. 12)

Também Paulo Freire nos lembra que a possibilidade de que os oprimidos experimentem a práxis (a ação tranformadora no mundo aliada à reflexão crítica sobre o mesmo) depende de uma crença real em suas capacidades:

é preciso que creiamos nos homens oprimidos. Que os vejamos como capazes de pensar certo também. Se esta crença nos falha, abandonamos a idéia ou não a temos, do diálogo, da reflexão, da comunicação e caiamos nos slogans, nos comunicados, nos depósitos, no dirigismo. (FREIRE, 1987, pg. 30)

A dificuldade de parte dos jovens em negociar suas questões não se apresenta, a nosso ver, como evidência de uma incapacidade argumentativa intrínseca, mas sim da carência de oportunidades para que descubram e desenvolvam competências que lhes são constantemente negadas, a ponto de que eles próprios ignorem que as possuem. A desigualdade estará sempre presente no contexto escolar, considerando a relação entre educadores (adultos, escolarizados, na maioria de classe média e com experiência profissional) e jovens ainda em formação oriundos de camadas populares. Mas reconhecer a desigualdade de habilidades discursivas entre educadores e jovens é reafirmar a necessidade radical de criar, nos processos formativos, contextos que lhes permitam desenvolvê-las. Percebemos ser de suma importância numa proposta de Gestão Coletiva que, a todo momento e em todos os âmbitos do processo formativo, os jovens sejam incentivados a falar e a argumentar, por meio de exercícios que potencializem situações de debate e da criação de canais efetivos de participação.

A maior força para a participação é o diálogo. Diálogo, aliás, não significa somente conversa. Significa se colocar no lugar do outro para compreender seu ponto de vista; respeitar a opinião alheia; aceitar a vitória da maioria; pôr em comum as experiências vividas, sejam boas ou ruins; partilhar a informação disponível; tolerar longas discussões para chegar a um consenso satisfatório para todos. (DÍAZ BORDENAVE, 1994, pg. 50)

Além da desigualdade de competências discursivas, é inegável a existência de hierarquias dentro da instituição escolar, que marcam uma diferença simbólica que define funções, níveis de participação e efetividade do poder de decisão. A proposta de Gestão Coletiva da Oi Kabum! BH, no entanto, coloca os sujeitos em situações que desestabilizam suas posições hierárquicas, provocando diversas inversões de papéis - os quais tradicionalmente se baseiam na divisão do trabalho e na fragmentação das áreas do saber. No momento de organização de uma reunião com as famílias dos jovens, por exemplo, as faxineiras da escola opinam sobre o panfleto de divulgação assim como o educador de design gráfico, ao passo que os coordenadores ajudam a preparar o lanche e a limpar as salas após a festa.

A desestabilização das hierarquias é um aspecto fundamental da proposta de Gestão Coletiva, permitindo uma diversificação das habilidades e competências desenvolvidas pelos jovens e por toda a 
equipe da escola. Mas o aspecto mais relevante desse exercício de inversão de papéis tem uma dimensão política: algumas dicotomias - que em geral colocam um dos polos em posição superior são rompidas, como aquelas entre o saber intelectual e o fazer prático, o especialista e o leigo, o masculino e o feminino.

O conceito de diálogo em Freire está ligado à noção de práxis, mas também à desconstrução da relação vertical entre educador e educando. A pedagogia libertadora não pode existir sem a prática do diálogo, e é por meio dela que o educador se reconhece também como educando, e o educando como educador. O diálogo transforma o educador em mediador (e não transmissor), o que modifica a situação gnosiológica do aprender:

a educação libertadora, problematizadora, já não pode ser o ato de depositar, ou de narrar, ou de transferir, ou de transmitir "conhecimentos" e valores aos educandos, meros pacientes, à maneira da educação "bancária", mas um ato cognoscente. Como situação gnosiológica, em que o objeto cognoscível, em lugar de ser o término do ato cognoscente de um sujeito, é o mediatizador de sujeitos cognoscentes, educador, de um lado, educandos, de outro, a educação problematizadora coloca, desde logo, a exigência da superação da contradição educador-educandos. Sem esta, não é possível a relação dialógica, indispensável à cognoscibilidade dos sujeitos cognoscentes, em torno do mesmo objeto cognoscível. (FREIRE, 1987, pg. 39)

Ao incentivar a expressão, o diálogo e a quebra dessa distância dada a priori entre os que dominam determinada área de conhecimento ou knowhow técnico e os leigos, a proposta de Gestão Coletiva encoraja os jovens a se arriscarem na realização de tarefas que sempre lhes foram negadas e os desperta para a possibilidade concreta de participação. Algumas falas em grupos focais demonstram que eles têm consciência dessa desestabilização de lugares simbólicos:

Aqui é bem aberto. Se está tendo um problema, a gente assenta e discute. Os professores não estão acima dos alunos. A gente aprende que assim como tem direitos, tem deveres. (Grupo Focal sobre Escola, Família e Comunidade, $1^{\text {o }}$ semestre/ 2011)

Pela abertura que a gente tem aqui de questionar, comecei a fazer mais isso na escola. Antes eu ficava com uma dúvida e guardava pra mim. Não acrescentava nem mudava nada. Agora é uma posição diferente, me sinto meio na obrigação de conversar com alguém sobre determinado assunto, de me posicionar, expor o que estou pensando. (Grupo Focal sobre Escola, Família e Comunidade, $2^{\circ}$ semestre/ 2011)

Notamos assim que alguns dos desafios encontrados na proposta de Gestão Coletiva precisam ser continuamente enfrentados por meio de alguns princípios importantes, como o incentivo à expressão e à argumentação, a desestabilização das hierarquias e consciência de que tanto a proposta quanto os sujeitos estão em permanente formação e transformação. 


\title{
Considerações Finais
}

Por meio deste estudo, buscamos mostrar como a proposta de Gestão Coletiva da Oi Kabum! BH é profícua na construção de aprendizados essenciais por parte de educandos e educadores, ligados à formação humana, política e profissional. Entre dificuldades de implementação, perspectivas abertas e desafios vividos cotidianamente, as vivências com a Gestão Coletiva na Oi Kabum! BH nos mostram que a experiência de participação é parte essencial da formação dos sujeitos. Como afirma Bordenave:

\begin{abstract}
A participação é o caminho natural para o homem exprimir sua tendência inata de realizar, fazer coisas, afirmar-se a si mesmo (...). Além disso, sua prática envolve a satisfação de outras necessidades não menos básicas, tais como a interação com os demais homens, a autoexpressão, o desenvolvimento do pensamento reflexivo, o prazer de criar e recriar coisas, e, ainda, a valorização de si mesmo pelos outros. Conclui-se que a participação tem duas bases complementares: uma base afetiva participamos porque sentimos prazer em fazer coisas com outros - e uma base instrumental - participamos porque fazer coisas com outros é mais eficaz e eficiente que fazê-las sozinhos. (DÍAZ BORDENAVE, 1994, pg. 16)
\end{abstract}

O fim último visado ao tornar pública esta experiência é o de fazer a educadores e profissionais da Educação uma proposta: que criem, para seus jovens educandos, possibilidades de participação, de discussão e argumentação, de reflexão coletiva e construção conjunta do espaço educacional compartilhado. Pois o que se percebe como fruto disso é que, encontrando oportunidades, os jovens podem se tornar cidadãos ativos, críticos, participativos, colaborativos e conscientes.

\section{Referências Bibliográficas}

ALVES-MAZZOTTI, Alda J.; GEWANDSZNAJDER, F. O método nas ciências naturais e sociais: pesquisa quantitativa e qualitativa. São Paulo: Pioneira, 1999.

DAYRELL, Juarez. Por uma pedagogia da juventude. Onda Jovem. São Paulo, n.1, p. 34-47, 2005.

DIAZ BORDENAVE, Juan E. O que é participação. $8^{\text {a }}$ ed. São Paulo: Brasiliense, 1994. (Coleção Primeiros Passos; 95).

FREIRE, Paulo. Pedagogia da autonomia: saberes necessários à prática educativa. São Paulo: Paz e Terra, 1996. . Pedagogia do oprimido. 17a. ed. Rio de Janeiro: Paz e Terra, 1987. 
LIMA, Rafaela Pereira (Org.). Mídias comunitárias, juventude e cidadania. Belo Horizonte: Autêntica/ Associação Imagem Comunitária, 2006.

RANCIÈRE, Jacques. O mestre ignorante - cinco lições sobre a emancipação intelectual.

Trad.: Lílian do Valle. 3. ed. - Belo Horizonte: Autêntica, 2010.

SANTOS, Boaventura de Sousa. Renovar a teoria crítica e reinventar a emancipação

social. São Paulo: Boitempo Editorial, 2007.

' Oi Kabum! - Escola de Arte e Tecnologia de Belo Horizonte/Pesquisadora

ii Para mais informações sobre o trabalho desenvolvido pelo Instituto Oi Futuro, acesse o site: www.oifuturo.org.br/.

iii Para mais informações sobre o trabalho desenvolvido pela AIC, acesse o site: www.aic.org.br.

iv O Plug Minas - Centro de Formação e Experimentação Digital é um projeto do Governo de Minas dedicado à juventude, inaugurado em junho de 2009. Para mais informações, acesse: www.plugminas.mg.gov.br.

v Os três grupos focais realizados para auxiliar a pesquisa aconteceram, respectivamente, ao final do primeiro, do segundo e do terceiro semestre do processo formativo da segunda turma, de modo que o primeiro deles foi realizado em julho de 2011, cerca de cinco meses após o ingresso dos jovens na Oi Kabum! BH. A seleção dos jovens foi aleatória. As entrevistas individuais foram realizadas no segundo semestre de 2011. Foram escolhidos quatro jovens, a partir da observação de sua atuação nos Grupos de Gestão. Escolhemos jovens que participavam intensamente das atividades, apresentando com frequência críticas e sugestões. Dos quatro jovens, três deles estavam participando ou haviam participado, no semestre anterior, do Conselho Gestor.

vi Já que dos diferentes modelos de democracia que se constituíram desde o fortalecimento da mesma no século XIX, apenas um deles permaneceu e dominou o cenário mundial: a democracia representativa liberal/ neoliberal, na qual democracia e capitalismo convivem e a redistribuição social, ao invés de ser garantida, é destruída. 


\section{Anexo 1 - Roteiro de Entrevista}

1) De qual grupo de gestão você participa? Que ações este grupo vem desenvolvendo?

2) Você acha que as ações deste grupo interferem diretamente no cotidiano e no funcionamento da escola? De que forma?

3) Qual foi a primeira vez em que você ouviu falar/ seu primeiro contato com a proposta de Gestão Coletiva?

4) Há outros espaços sociais que você frequenta onde existe uma Gestão Coletiva? Que outras experiências de Gestão Coletiva você teve? Em que medida elas se aproximam e se diferem da experiência na Kabum?

5) Quais aprendizados e habilidades você acha que a participação no grupo te traz?

6) Essa participação e esses aprendizados modificaram de alguma forma sua relação com a escola (o espaço físico, as pessoas, as atividades formativas etc)? Como? Dê exemplos.

7) Essa participação e esses aprendizados modificaram de alguma forma suas relações familiares e pessoais? E suas relações profissionais? Como? Dê exemplos.

8) Em sua opinião, quais as maiores dificuldades e problemas enfrentados pela Gestão Coletiva na Oi Kabum? Qual a causa destas dificuldades? Há algo que pode ser feito para solucionálas?

9) Você se sente participando efetivamente da gestão da escola? Por quê?

10) Para você, em que espaços e de que formas essa participação acontece ou deveria acontecer?

11) Para você, o que é o Conselho Gestor? Por que ele existe? Quais as suas funções?

12) Tais funções vem sendo bem exercidas? A atuação do Conselho Gestor corresponde às expectativas que você tem em relação a ele? Por quê?

13) O que poderia ser feito para melhorar a Gestão Coletiva na Oi Kabum! BH?

\section{Anexo 2 - Roteiro de Grupo Focal}

1) De qual grupo de gestão vocês participam? Que ações estes grupos vem desenvolvendo?

2) Vocês acham que as ações deste grupo interferem diretamente no cotidiano e no funcionamento da escola? De que forma?

3) Quais aprendizados e habilidades vocês acham que a participação no grupo traz?

4) Quais decisões foram tomadas na escola com a participação de vocês? Deem exemplos de resoluções das quais vocês participaram, discutiram, opinaram. Como foi o processo de discussão destas decisões?

5) Como vocês vêem a participação de vocês na gestão coletiva? O que motiva a participação de vocês? O que movia vocês para desempenhar as tarefas do grupo em que estavam?

6) Essa participação e esses aprendizados modificaram de alguma forma a relação de vocês com a escola (o espaço físico, as pessoas, as atividades formativas etc)? Como? Dê exemplos.

7) Essa participação e esses aprendizados modificaram de alguma forma suas relações familiares e pessoais? E suas relações profissionais? Como? Dê exemplos.

8) O que significa a palavra "gestão", para vocês?

9) Qual foi a primeira vez em que vocês ouviram falar da proposta de Gestão Coletiva? Há outros espaços sociais que vocês frequentam onde existe uma proposta de Gestão Coletiva? Que outras experiências de Gestão Coletiva vocês tiveram? Em que medida elas se aproximam e se diferem da experiência na Kabum?

10) Por que vocês acham que a Oi Kabum! está construindo esse trabalho de gestão coletiva?

11) Vocês se sentem participando efetivamente da gestão da escola? Por quê? 
12) Para vocês, em que espaços e de que formas essa participação acontece ou deveria acontecer?

13) Para vocês, o que é o Conselho Gestor? Por que ele existe? Quais as suas funções?

14) Tais funções vem sendo bem exercidas? A atuação do Conselho Gestor corresponde às expectativas que vocês têm em relação a ele? Por quê?

15) Quais as maiores dificuldades e problemas enfrentados pela Gestão Coletiva na Oi Kabum? Qual a causa destas dificuldades? Há algo que pode ser feito para solucioná-las?

16) $\mathrm{O}$ que vocês acham que não pode mudar nunca? O que funciona muito bem?

17) O que poderia ser feito para melhorar a Gestão Coletiva na Oi Kabum! BH? 